\title{
Standing in the Tension
}

\author{
Pentecost and Peace
}

WINTERBOURNE HARRISON-JONES

As both a faith leader and researcher, I stand at the intersection of the empirical and that which can oftentimes not be explained. I have thought long about how we as researchers might begin to capture the pathos of this moment in time. To say that 2020 has been a year like no other would be a gross understatement. The world in which we live is filled with pain, misery, and despair. Everywhere we look, we are constantly bombarded by reminders that we do indeed live in a broken and dark world. All over the globe, people on every continent and of

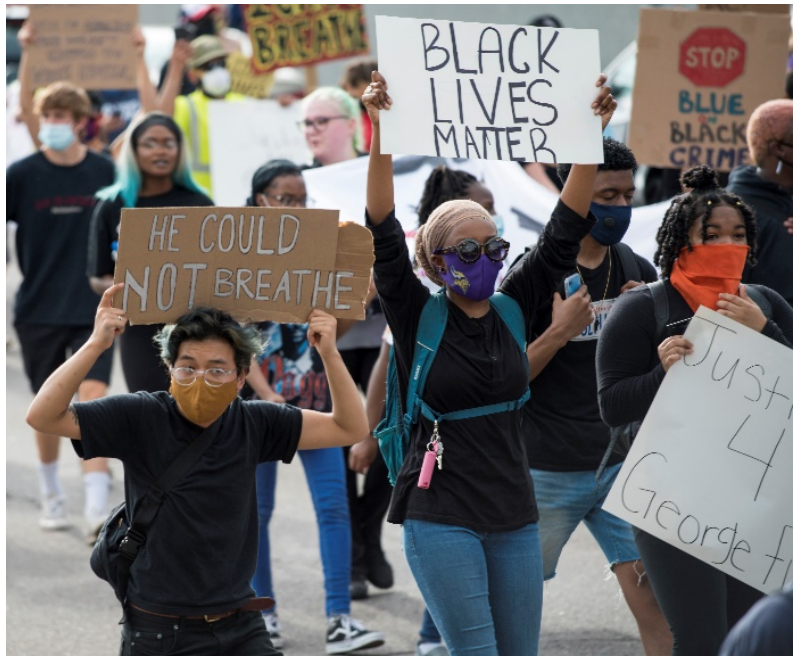

People protesting against police violence after the death of George Floyd. every walk of life are in search for a light of hope and a break from the madness of our times.

The cruel realities of our fractured humanity have been made known again and again and the lament and voices of the people can be felt and heard all over the globe. The "three threats" as Dr. King called them of "racism, poverty and militarism" have seemingly collided again and have awakened the moral tempest of this nation. Like the tonga drums of Zimbabwe, I can hear ancestral rhythms pulsating in the air. The fires of Pentecost race and rage through the world - for in the words of the old Negro Spiritual, "God gave Noah the rainbow sign. No more water, the fire next time." Pentecost is here!

\section{Author}

WINTERBOURNE

HARRISON-JONES

Doctoral student in the IU

School of Education at IUPUI Urban Education Studies program

Community Engaged Participatory Research informs me that my job as a researcher is not to dominate or dictate the way forward, but rather to come alongside the community as a partner, to illuminate and elevate the voices and the people, and to lend whatever agency I have towards their cause and 
On every continent and in every city, people of every culture and of every nationality battle with and suffer from the effects of educational disparity and racial inequality; economic insecurity and lack of political diplomacy; worldly insobriety and no regard for human dignity; ethical deformity with no reverence to cosmic divinity; the absence of morality and the prevailing-deviation from authenticity; lack of individual sanctity and the over-abundance of vulgarity; communal animosity coupled with religious bigotry - yes, it is indeed hard to sing songs of hope in a strange land.

Pentecost is here! I speak not merely in religious terms, but I speak with the voice of the Prophets of old - Moses, Muhammad, Isaiah, Maya, Joel, Amos, Nikki, Mari, Micah, Nina, Malcolm, James, Medgar, and Fannie - that foretold of the day when the winds of change would blow so ferociously throughout the earth that it would be impossible to deny that something new was coming.

In this kairos moment, we must ask ourselves, how might Community Engaged Participatory Research equip us to think intentionally and prophetically about our work? In the days following the brutal lynching of George Floyd the Emmett Till of 2020 - the streets of this nation burst with protests and civil demonstrations calling for justice.

I walked the streets of downtown Indianapolis and collected many of the signs left behind by the protesters. One sign had a quote by the American author and anthropologist, Zora Neale Hurston, which read, "If you are silent about your pain, they'll kill you and say you enjoyed it." As many around the nation began to ask where we go from here, I too pondered this thought, but then I realized that it is not up to me to decide.

Community Engaged Participatory Research informs me that my job as a researcher is not to dominate or dictate the way forward, but rather to come alongside the community as a partner, to illuminate and elevate the voices and the people,

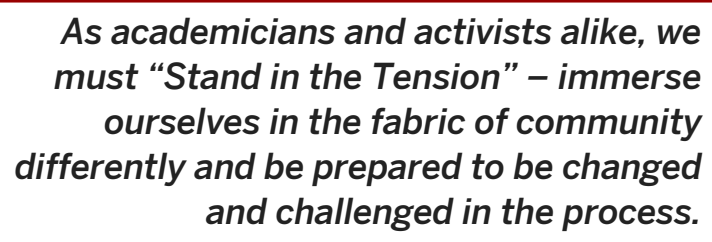

As academicians and activists alike, we must "Stand in the Tension" - immerse ourselves in the fabric of community differently and be prepared to be changed and challenged in the process.

and to lend whatever agency I have towards their cause and truth.

A few days later I was invited to offer a homily in response to the social unrest throughout the country. In preparing my thoughts, inspired by the signs I collected, I shared with those gathered that there is always a haste to move too quickly towards solving the problem or enacting our savior mentality.

Remembering the words of Hurston, I instead encouraged those in attendance to "stand in the tension" - to listen deeply and to be still together. In respond to this, a dear friend - Linda Rinker - who was listening that day and who in response to the words I shared, penned this poem entitled, "Stand in the Tension."

The winds of change are sweeping across the world

and the fresh leaves of early summer are tossed by anger and hope. Look! Plague and protest are moving; nothing will be the same. Stand in the tension; hear the voices in the wind. Wait! Listen! Take the anguish and the anger into your soul. Embrace the tears of the world. Let your heart become transparent as water, absorbing the world's suffering.

Stand in that grief, that despair, until you are transformed, changed forever. Let the breath of God blow through you in cleansing thunder and rain.

Then will come the time to act, and you will know the way.

Though the themes of this poem are religious in nature, they likewise speak to the foundational principles of Community Engaged Participatory Research. I would argue that this moment invites us to "Stand in the Tension" together - or in the words of Mari Evans - "to explode/in the majesty of our oneness - our comingtogether - in a comingtogetherness." 
The winds of change cannot be ignored, and as community researchers we must be open to new ways of understanding, new ways of becoming, and new was of envisioning the future.

Though our current state is dire, it need not stay this way. We need not journey through these days as those who are helpless and hopeless. It is not peace as a pacifier for change that we are after, but peace as a prophetic mandate, peace as spiritual practice, peace as lived experience, and peace as liberation. Though we try with all our might to fight off feelings of despair and utter loss, I still believe that there is still a light that shines in the darkness, there is still truth to be found, and there still hope to be captured - but it is not given, it must be forged.

We have been this way before. Whether rhythmically captured through the sermons of the slave-preachers like John Jasper or thunderously delivered through passionate oratory like Malcolm X, Fannie Lou Hamer and Ella Baker; whether put to paper by social reformists like Booker $\mathrm{T}$.

Washington, Marcus Garvey and W.E.B DuBois or placed within a musical score by cultural icons like Nina Simone, Billie Holiday and Gil Scott Heron; whether spoken to tens-of-thousands on the steps of the Lincoln Memorial like Dr. Martin Luther King, Jr. or through the dangerous snake-infested swamps of the American south like Harriet Tubman - the catharsis of the human spirit - like the Phoenix and the Sphinx- always prevails.

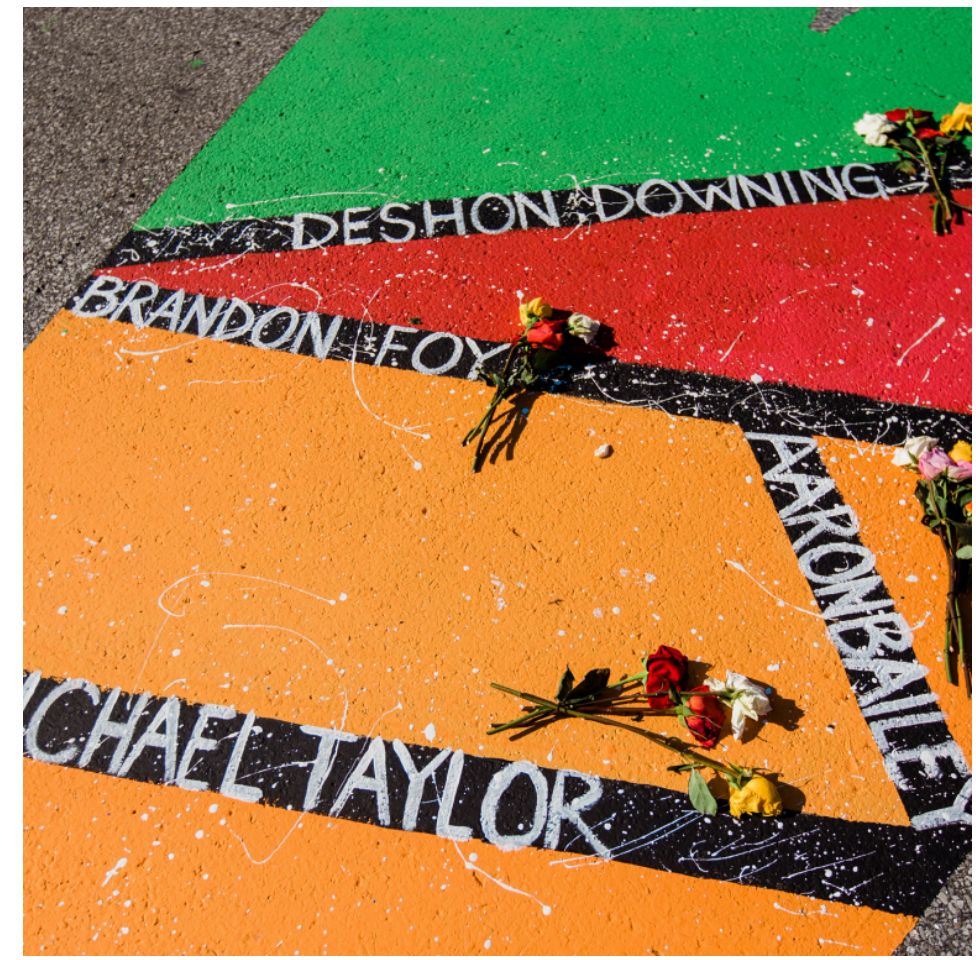

A mural painted in Indianapolis to honor those killed by police violence.

The fire of Pentecost is not meant to scare us, but to invite us all closer, to destroy the old, and ignite something new within our hearts. As academicians and activists alike, we must "Stand in the Tension" - immerse ourselves in the fabric of community differently and be prepared to be changed and challenged in the process. 